\title{
Relationship between Land Cover Changes with Water Quantity in Lake Victoria-A Case Study of Mara River Basin in Tanzania
}

\author{
Martine Hagai \\ School of Earth Sciences, Real Estate, Business and Informatics, Department of Geospatial Sciences and Technology, Ardhi \\ University, Dar es Salaam 35176, Tanzania
}

\begin{abstract}
LV (Lake Victoria) is valuable to the East African sub region and Africa in general, sources of water for LV are from its catchment areas and tributaries e.g. Kagera and Mara Rivers on Tanzania part. Apparently, catchment areas in proximities of LV and on MR (Mara River), indeed on MRB (Mara River Basin) in particular, are experiencing increased anthropogenic activities such as mining, fishing, settlements, agriculture etc., which lead to increased water usage, land degradation and environmental pollution. Such activities threaten the sustainability of the environment surrounding MRB and impliedly LV and its ecosystem. The level of water in LV is reported to be declining threatening its extinction. This paper is reporting on a study undertaken to establish the relationship between land cover changes with ground water discharge from specifically MRB into LV over the period of 24 years, i.e. 1986 to 2010. Methodology used is assessment of vegetation changes by using remote sensing through analysis of TM (Thematic Mapper) Landsat Images of 1986, 1994, 2002 and 2010 ETM (Enhanced Thematic Mapper) Landsat images, from which respective land cover change maps were generated and compared with ground water levels from MRB. Results indicates that there is a significant decline of land cover and ground water flowing into LV from MRB, and that there is positive correlation between land cover changes and the quantity of ground water flowing from MRB to LV. This phenomenon is common to all tributaries of LV, thus leading to decline of water in LV. It is recommended that relevant government institutions should endeavor formulating policies to control excessive use of wetlands and drylands in the proximity of LV and MRB in particular, such that the flow of water to LV may be sustained.
\end{abstract}

Key words: Land Cover Changes, Ground Water, Remote Sensing, LV (Lake Victoria), MRB (Mara River Basin)

\section{Introduction}

MRB (Mara River Basin) is composed of wetlands and drylands. Whereas the wetlands are used as water catchment areas for LV (Lake Victoria), drylands are used by surrounding communities for socio-economic activities such as settlements, mining, agriculture and so on.

Sustenance of $\mathrm{LV}$ water and its environment is critical, as it supports the Great Lakes countries in several ways such as provision of water for domestic use, agriculture, irrigation, fishing, transportation and others. As such, concerted efforts are required to

Corresponding author: Martine Hagai, Ph.D., research fields: geoinformatics, remote sensing and GIS. ensure its sustainability. Sustainability of the LV entails sustaining its water, which in turn depends on water flowing into it from its respective tributaries

It is a well known fact that vegetation is related to ground water discharge [1-4]. This is because of its direct and indirect influence on soil type which together with that vegetation roots structure has the capacity of withholding ground water. However, as observed by Mutie, S. M. [5], ground water is directly related to vegetation species on the ground surface. This means that there is interaction between vegetation and groundwater discharge; there is evidence that changes in vegetation alter both recharge rates and water-table depths [6]. The effects 
of vegetation dynamics on ground water can either be positive or negative. Vegetation also intercept rainfall and leaks out water obtained from the rooted profile (including soil, regolith, saprolite and rock fractures), and also facilitates infiltration (by improving soil condition and creating surface storage opportunities) whereas plant root systems increase percolation rates by creating macropores. It is noteworthy that, tilled ground surface tends to retain more water than bare soil and improves conditions of water infiltration into the soil. Roots provide channels for the preferential flow of water through the unsaturated zone to the water table, particularly in low-permeability soils, thereby increasing recharge rate. Therefore holding of water in wetland depends on the vegetation and soil structure, which implies that there is relationship between vegetation and ground water. In general, vegetation cover holds ground water quantity. However, the capacity and the trend of vegetation holding water is dependent on soil and vegetation roots structure. This capacity and trend of withholding water for MRB is unknown.

The liberazation of the Tanzania economy has resulted into proliferation of various small, medium and large scale mining activities within the MRB, such as the North Mara Gold Mines and others which subsequently have attracted into population increase in the basin. For example, in the past 10 years, the population of over 800,000 people in the MRB is reported by Maro, P. S. [7]. The growing population relies on respective wetland and dry lands for their livelihood activities; all of which of have direct impacts on vegetation cover changes resulting into vegetation dynamics which subsequently alter ground water flowing into LV.

LV Water level is reported to be declining threatening communities relying on it for various socio-economic activities [8]. Water for LV emanates from both ground and surface water from its catchment areas and tributaries. Surface water is largely dependent on rainfall, which also has been declining due to global factors particularly climate changes [9].

Owing to the fact that land cover has ability of withholding ground water, it is logical relating the decline of water in LV partly due to changes in vegetation cover within its surrounding environments (including its tributaries and water catchment areas e.g. MR and MRB). However, the relationship of land cover and ground water quantity varies from one place to another, and the exact relationship between land cover changes with groundwater in the MRB is not known. This is the problem which this work was set to establish so that authorities responsible for overseeing the LVB e.g. LVBC (Lake Victoria Basin Commission), WWF (World Wildlife Foundation) and others may formulate strategies for effective sustainable management of MRB, implicitly for the $\mathrm{LV}$ water. The problem of vegetation changes and its effect on LV water quantity was conceived from a research study recommendation by Makalle, A. M. P. [10], which insisted that all concepts such as the biodiversity management, streams flow, water reduction activities, and the interrelationships between land cover and all water resources must to be further studied for developing sustainable protection mechanism for LV.

\section{Research Design}

Due the fact that different vegetation types have varying capabilities of withholding ground water, it was logical directly relating the decline of water in LV with vegetation cover changes. Thus, in this regard, parameters of this study were land cover changes and corresponding ground water quantity. As there were no means of directly quantifying ground water, it was indirectly inferred from observed water levels of MR and relating it with analysis of vegetation cover changes over the study period. Subsequently, the methodology of this study was largely based on assessment of vegetation cover changes vis as vis MR water levels. 

River Basin in Tanzania

\section{Methodology}

The methodology involved assessment of vegetation cover changes in the MRB and relating it with respective water quantity in MR. Assessment of vegetation cover changes was effected using Remote Sensing Techniques. Satellite Images used were Landsat TM of the years 1986, 1994, 2002, and due to lack of data covering the study area, the study was compelled to use a slightly different sensor i.e. Landsat TM (Thematic Mapper) and Landsat ETM (Enhanced Thematic Mapper) satellite images for 2010, all the images were processed and classified into thematic classes typical of MRB area [11-13]. The methodology, however, disregarded storm water flowing into LV from Mara River. In this respect, water emanating from the entire MRB was sorely based on measured water levels at a gauge located at Kirumi Bridge (a point where MR enters LV (Fig. 1)), on assumption that the source of water for $M R$ is exclusively from ground water. Apart from Kirumi bridge gauge station, there were other water level measuring gauges at stations within LVB such as at Grumet, Mbarageti, Mori, Mara Mines, Suguti and Musoma port for monitoring ground water flowing from respective rivers into LV. Water levels data from Kirumi gauge was then related with vegetation dynamics data as computed from land cover changes.

\section{Reliability of Water Level Data observed at Kirumi Recording Station}

Regarding water levels data from Kirumi gauge, it was noted that the data had gaps due following anomalies:

\section{a. Ineffective Data Management}

This was due to following reasons:

(i) The Data was being recorded by casual gauge workers who were not aware of the importance of the data they were recording, as such; they were not adequately motivated to comprehend that the data collected needed to be continuous [14].

(ii) Non-accountability arising from the fact that gauge readers are answerable to their respective Regional Water Authorities, while the main custodian of the data is the $\operatorname{LVBC}[15,16]$. This was perceived as a mere administrative problem which had an effect of reduction of enthusiasm towards data recording.

b. Inflow and Outflow Nature of LV Water

It was noted that MR water has outflow and inflow characteristics. During outflow phenomenon, which depends on the forces acting on the lake, water moves some distance either northwards or southwards or Eastwards or Westwards. This phenomenon seemed to have affected gauge readings possibly (refer to Fig. 1 for the opening which facilitates inflow and outflow phenomenon). This is believed to have adversely influenced subsequent interpretations from the data, which significantly deviated from theoretical known situations [17-19].

The above anomalies then rendered ground water level data recorded at Kirumi gauge to be discarded. Instead, LV water quantity was inferred from partial water spatial extents of the lake as drawn from classified satellite images as extracted from relevant epochs.

Spatial extents were used to infer water quantity under assumption that quantity of water is directly proportional to spatial water extent and that water depth variation is insignificant (See Fig. 2 for spatial shift of LV water boundary over the study epochs).

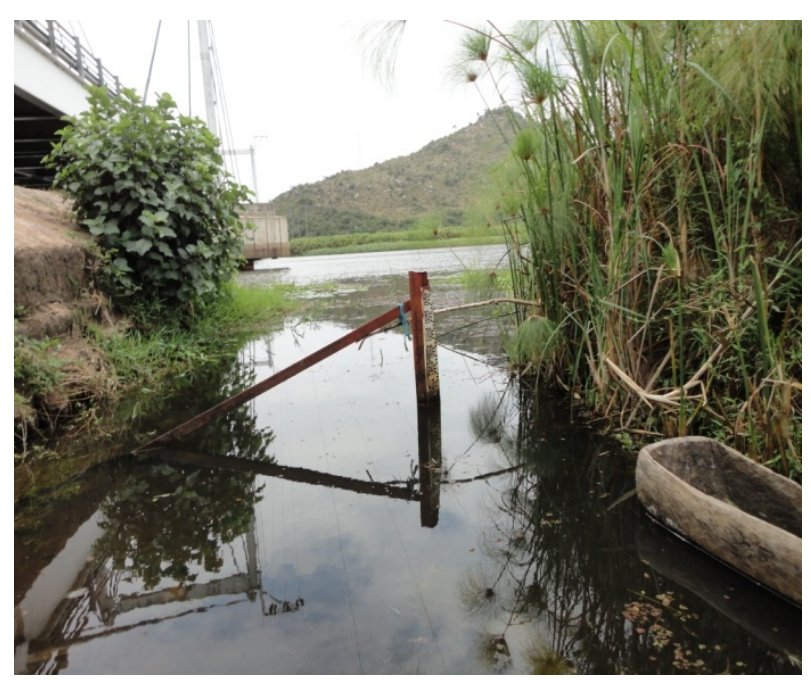

Fig. 1 The Kirumi water level measuring gauge. 


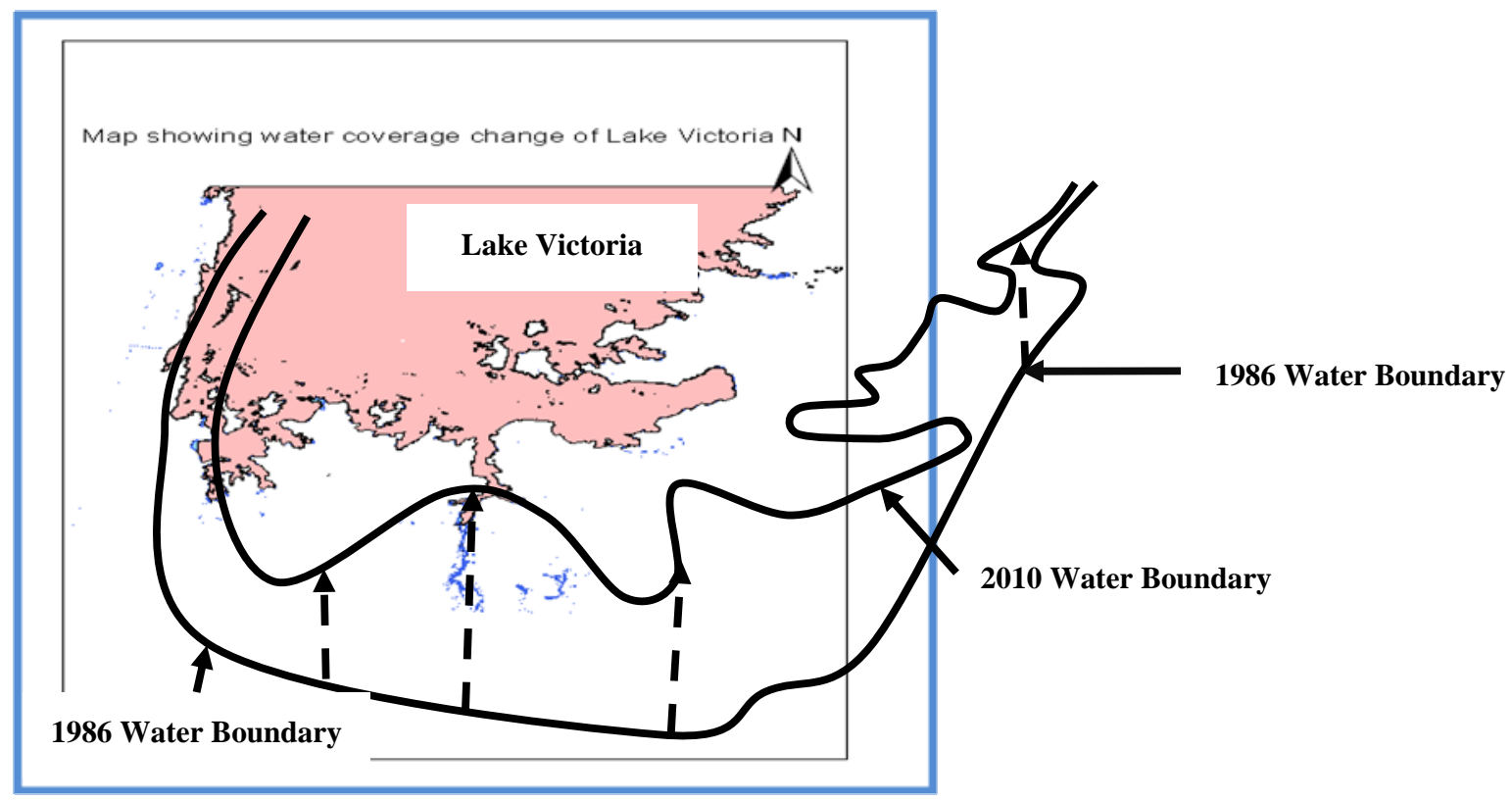

Fig. 2 Trend of spatial shifts of LV water extent (on Tanzania side) from 1986 to 2010.

\section{Data Processing and Analysis}

This involved firstly adaptation of data for subsequent analysis and secondly quantification of land cover changes over the study period. With regard to satellite image data, they were first preprocessed for radiometric and geometric inconsistencies as well as restoration and secondly they were classified. Image classification was preceded by identification of potential thematic classes typical of MRB which are cultivated areas, bush land, grasses, water, bare land and swamps.

Training data were collected from field visit to the area and others were from existing data sources specifically topographic maps. Ground truth data was used in determination of class spectral signatures which was used in supervised classification of all images whose outputs are as presented in Figs. 3-6.

All the classification results were validated by accuracy assesment using the subset of the ground truth dataset as check points. Classification Accuracy obtained were over 80 percent, which was a testimony of the success of the classification exercise. This was followed by image differencing of classified images to determine land cover changes over time which inferred vegetation dynamics [20-24].

\section{Results}

This involved a process of change detection of land cover in the MRB over the study period. As mentioned earlier on, land cover change detection was based on classified image differencing i.e. each classified image was differenced from its respective previous image. The results of image differencing are as shown in Table 1.

For purpose of simplifying subsequent analysis woodland and grass classes were combined formulating vegetation class; also water class was combined with swamps yielding water class; combination of classes was done to create manageable classes, in the course of this only four classes were left which were cultivated areas, vegetation, water and forests.

\section{Discussion of Results}

The results demonstrated that water areas, forests and vegetation generally declined, while cultivated areas increased over the study period. This is testimony that there are excessive land use activities in the fringes of MR and MRB resulting from increased population in the area, which subsequently degrades 


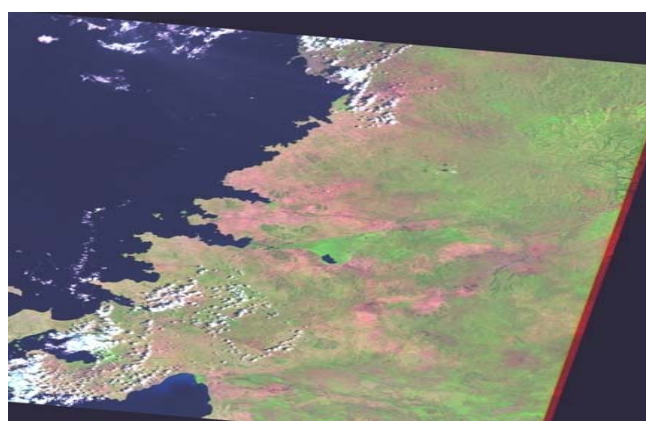

Fig.3 Clasified Landsat TM of 1986.

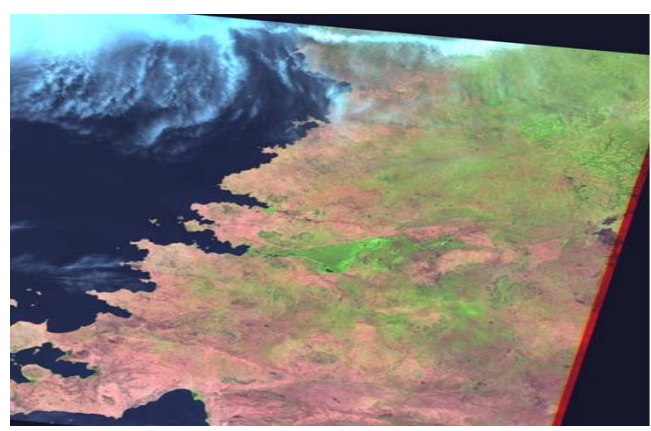

Fig.4 Clasified Landsat TM of 1994.

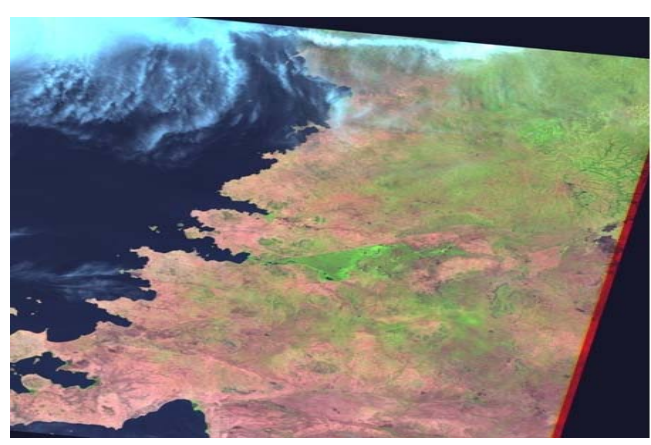

Fig. 5 Clasified Landsat TM of 2002.

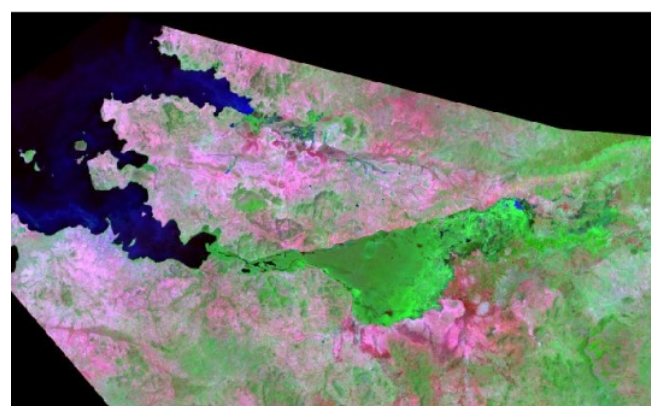

Fig.6 Clasified Landsat ETM of 2010.

Table 1 Summary of vegetation changes.

\begin{tabular}{lllll}
\hline Year & Cultivated & Water & Vegetation & Forests \\
\hline 1986 & 819 & 8,001 & 6,713 & 5,702 \\
1994 & 1,229 & 8,324 & 5,980 & 4,262 \\
2002 & 1,525 & 7,878 & 6,470 & 3,843 \\
2010 & 4,820 & 6,566 & 1,484 & 2,929 \\
\hline
\end{tabular}

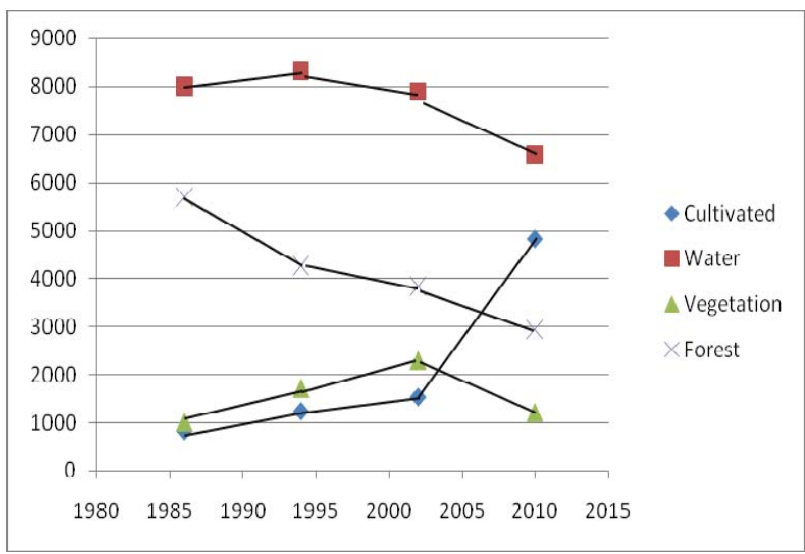

Fig. 7 Graphical plot of land covers dynamics.

the environment, specifically, the water catchment areas for LV. This has adverse effect on the sustainability of LV. Summary of land cover changes are as graphically presented as shown in Fig. 7.

Spatial water extents were directly linked with water quantity in relative terms, the results of which are shown in Fig. 7.

\section{Conclusions}

In the light of the analysis above, it is being concluded that there is a notable decline of vegetation over the study period, which indirectly infers a similar decline of ground water flowing from MRB to LV over the same period. This phenomenon has a long term adverse effect of reducing the quantity of water in LV.

Additionally, more areas have been converted into cultivation particularly from 2002 onwards for increased socio-economic activities in the MRB leading to land degradation.

Land cover dynamics is prevalent in the environments of MRB threatening the ecosystem of the area. There is indication of a positive correlation between ground water and vegetation in MRB.

\section{Recommendations}

Encourage effective land use management in the MRB area from either the local government level or institutional level so as to protect the area from environmental degradation. Effective land use 
management should be used to reduce further vegetation depletion in MRB and other catchment areas thereby indirectly protecting ground water flowing to LV from respective catchment rivers. As the water for LV is from both ground as well as surface water which is much dependent on availability of rainfall which in turn is affected by global climatic changes, it is recommended that a study be conducted to establish how climatic change have affected surface water quantity which flows from catchment rivers to LV.

\section{Acknowledgement}

The author thanks the LVBC for financial support which enabled the field work undertakings. LVBC offices in Mara region played a key role of providing pertinent literature which formed the knowledge base for undertaking this research. Special acknowledgements go to Ardhi University Directorate of Postgraduate Studies for logistical support.

\section{References}

[1] Jobbagy, E. G., and Jackson, R. B. 2004. "Ground Water Use and Salinisation with Grassland Afforestation.” Global Change Biology 10: 1299-312.

[2] Kashaigili, J. J. 2006. "Land Cover Dynamics and Hydrological Functioning of Wetlands in Usangu Plains in Tanzania.” Ph.D. Dissertation, Sokoine University of Agriculture.

[3] Moser, S. C. 1996. “A Partial Instructional Module on Global and Regional Land Use/Land Cover: Assessing the Data and General Relationships.” Geojournal 39 (3): 241-3.

[4] Twesigye, C. K., Onwere, S. M., Getenga, Z. M., Mwakalila, S. S., and Nakiranda, J. K. 2011. “The Impact of Land Use Activities on Land Cover and Water Quantity on Lake Victoria Watershed.” The Open Environmental Engineering Journal 4 (1): 66-72.

[5] Mutie S. M. 2006. "Land Cover Effects on Flow Regime of Mara River.” In Proceedings of the 2nd International ISCRAM Conference.

[6] Riebsame, W. E., Meyer, W. B., and Turner, B. L. 1994. "Modeling Land-use-Soil as part of Global Environmental Change.” Climate Change 28: 45.

[7] Maro, P. S. 1974. "Population and Land Resources in Northern Tanzania: Dynamics of Change, 1920-1970.” Master's thesis, University of Minnesota.
[8] Charles, H. S. 2006. "Water Level of Lake Victoria Dropping Faster.” The Open Environmental Engineering Journal 2014 (3): 13-9.

[9] Townsend, P. A. 2002. "Relationship between Forest Structure and Detection of Flood Inundation in Forested Wetlands Using C-band SAR.” International Journal of Remote Sensing 23 (2): 443-60.

[10] Makalle, A. M. P., Obando, J., and Bamtaze, Y. 2008. "Effects of Land Use Practices on Livelihoods in the Transboundary Sub-catchments of Lake Victoria, Basin.” Journal of Environmental Science and Technology 2: 309-17.

[11] Singh, A. 1989. "Digital Change Detection Using Remotely sensed data." International Journal of Remote Sensing 6: 989-1003.

[12] Thomas, M. L., and Ralph, W. K. 1994. Remote Sensing and Image Interpretation. New York: John Wiley and Sons.

[13] Tahir, M., Imam, E., and Hussan, T. 2013. "Evaluation of Land Use/Land Cover Changes in Mekelle City, Ethiopia Using Remote Sensing and GIS.” Computational Ecology and Software 3 (1): 9-16.

[14] Brockington, D. 2005. "Corruption Taxation and Natural Resources Management in Tanzania.” Journal of Development Studies 44 (1): 103-26.

[15] De Vries, M. S. 2000. "The Rise and Fall of Decentralization: A Comparative Analysis in European Countries.” European Journal of Political Research 38 (2): 193-224.

[16] Leah, M., Mearns, R., and Scoones, I. 1999. "Environmental Entitlement: Dynamics and Institutions in Community-based Natural Resource Management.” World Development 27 (2): 225-47.

[17] Rodriquez-Iturbe, I. 2000. "Ecohydrology Perspective of Climate Change-soil-vegetation Dynamics.” Water Resources Research 36: 3-9.

[18] Mango, L. M., Melesse, A. M., Maclain, M. E., Gann, D., and Setegn, S. G. 2011. "Land Use and Climate Change of Upper Mara River basin, Kenya: Results of a Modeling Study to Support Better Resource Management.” Hydrological Earth Systems Science 15: 2245-58.

[19] Dedhwal, V. K., Aggarwal, S. P., and Mishra, N. 2010. Hydrological Simulation of Mahandi River Basin and Impact of Land Use/Land Cover on Surface Run off Using Micro Scale Hydrological Model. Vienna: IAPRS.

[20] Kiage, L. M., Liu,, K. B., Walker, N. D., Lam, N., and Huh, O. H. 2007. "Recent Land Cover/Use Change Associated with Land Degradation in the Lake Baringo Catchment, Kenya East Africa: Evidence from Landsat $\mathrm{TM}$ and $\mathrm{ETM}^{+}$." International Journal of Remote Sensing 28 (19): 4285-309. 

River Basin in Tanzania

[21] Hebinck, P. 2007. Investigating Rural Livelihood and Landscape in Guquka and Koloni: An Introduction. Brill Academic Publishers, 1-33.

[22] Chavula, G., Brezonik, P., and Bauer, M., 2011. "Land Use and Land Cover Changes in Lake Malawi Drainage Basin 1982-2005.” International Journal of Geosciences 2: 2-178.

[23] Kashindye, A., Mtalo E. G., Mpanda, M. M., Liwa, E., and Gilaba, R. 2013. "Multitemporal Assessment of
Forest Cover, Stock Assessment of Forest Cover, Stock Parameters and Above Ground Biomass Dynamics in Miombo Woodlands in Tanzania." Africa Journal of Environmental Science and Technology (AJEST) 7: 611-23.

[24] Chavula, G. B., and Brezonik, P. M. 2011. "Land Use and Land Cover Changes (LULC) in Lake Malawi Drainage Basin, 1982-2005.” International Journal of Geosciences 2: 172-8. 